\title{
Does the Combination of Intracorneal Ring Segments and Photorefractive Keratectomy have a Synergistic Effect on Keratoconus Progression?
}

\author{
Sina Elahi, Olivier Rahimian, David Touboul, David Smadja
}

\section{ABSTRACT}

We report the case of a 32-year old woman with bilateral severe keratoconus, who was implanted with intracorneal ring segments 10 years ago, followed by a high-PRK ablation of 8-diopters. Twelve years later, the refraction and topographic outcomes remained stable. The hypothetic mechanisms for explaining the corneal stability over time after this unusual combined treatment for keratoconic cornea is discussed.

Keywords: Intrastromal corneal rings, Keratoconus, PRK, Ectasia, Orbscan, Refractive surgery.

How to cite this article: Elahi S, Rahimian O, Touboul D, Smadja D. Does the Combination of Intracorneal Ring Segments and Photorefractive Keratectomy have a Synergistic Effect on Keratoconus Progression?. Int J Kerat Ect Cor Dis 2013;2(2): 92-94.

\section{Source of support: Nil}

Conflict of interest: None declared

\section{INTRODUCTION}

Intrastromal corneal ring segments (ICRS) were first reported in 1989 by Flemming et $\mathrm{al}^{1}$ for the correction of myopia. Later, Colin et al has reported the use of this technology for the treatment of keratoconus. ${ }^{2}$ The refractive and biomechanical response to ICRS implantation in ectatic corneas has since been widely studied. ${ }^{3,4}$ However, more recently, the potential halting effect of ICRS on the progression of the ectatic disease has been raised by several reports, ${ }^{5,6}$ but its mechanism remains not fully understood. Photorefractive keratectomy (PRK) is a surgical technic widely performed for more than 20 years and its long-term effects on the cornea have been extensively studied. ${ }^{7,8}$ However, although commonly recognized as a relative counter indication in ectatic corneas, ${ }^{9,10}$ it has been successfully used with and without corneal cross linking in mild to moderate keratoconus for improving the visual acuity and quality. ${ }^{11,12}$ Indeed, despites the few cases reported of post-PRK ectasia in the literature, ${ }^{13}$ the potential relative halting effect of the PRK has been questioned..$^{14,15}$

To further feed the controversy and illustrate theses hypothetic halting effects of both ICRS implantation and PRK, we wanted to report the case of a keratoconic patient that received a sequential treatment with ICRS implantation followed by a 8 D PRK ablation and who remains stable for more than 10 years.

\section{CASE REPORT}

A 32-year-old woman with bilateral keratoconus and who was contact lenses-intolerant was implanted with two intracorneal ring segments (INTACS, KeraVision, Inc, Fremont, CA, USA) in the left eye in 2001 for improving her vision. The rings were placed at $380 \mu$ depth with an incision performed at $90^{\circ}$. Preoperatively, maximal keratometry measured with the Orbscan topographer (Bausch and Lomb, Rochester, NY) in her left eye was $60 \mathrm{D}$ with a cylinder of -9 D (Fig. 1, left) with a best spectacle corrected visual acuity (BSCVA) inferior to 20/200 an a refraction of -10 ( -7 $\times 180^{\circ}$ ). At 1 year postoperatively, the BSCVA improved to $20 / 100$ with $-9\left(-5 \times 180^{\circ}\right)$ and the maximal keratometry and corneal astigmatism decreased, respectively by $7 \mathrm{D}$ and 2 D (Fig. 1, right).

However, 4 years later, the correction being still too high with glasses, she underwent a PRK with application of mitomycin $0.02 \%$ for 2 minutes. Preoperative refraction was stable with $-9\left(-5 \times 180^{\circ}\right)$ and a thinnest point measured at $338 \mu$ with the Orbscan. The maximal ablation depth achieved was $147.1 \mu$ with a residual stromal bed (overall postoperative corneal thickness below the epithelium), measured in optical coherence tomography (Visante OCT, Carl Zeiss Meditec), of $268 \mu$. At 1 year postoperatively, the BSCVA was $20 / 25$ with a slight overcorrection of +2 $\left(-3 \times 180^{\circ}\right)$. Orbscan map (Fig. 2, left) showed a maximal keratometry of $42.2 \mathrm{D}$ with a corneal astigmatism of 4.1 D. Seven years after the photorefractive keratectomy, a surprising stability was observed with a BSCVA of 20/20, a refraction of $+1.75\left(-3 \times 180^{\circ}\right)$ and a spherical equivalent of nearly zero. Topographic findings in Orbscan maps confirm the relative stability of the cornea, with a maximal keratometry of $42.8 \mathrm{D}$ and a cylinder of $4 \mathrm{D}$ (Fig. 2, right).

\section{DISCUSSION}

While high PRK ablation is expected to weaken the cornea and therefore causing a more rapid progression of the ectasia that would have otherwise occurred, ${ }^{16}$ we report the case of a surprising corneal stability more than 7 years after high myopic surface ablation.

Although cases of ectasia after PRK have been reported in the literature, ${ }^{9,13}$ surface ablations on keratoconus 


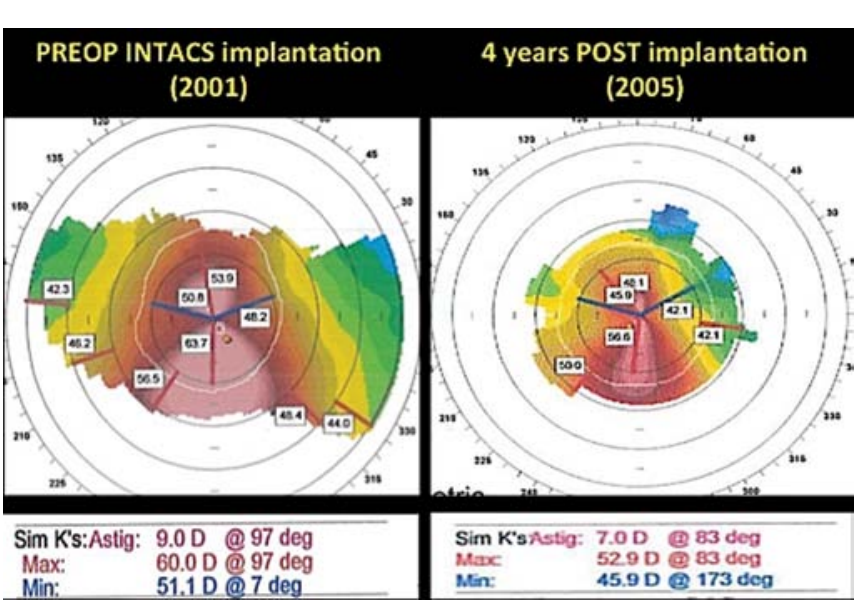

Fig. 1: Preoperative (left) and postoperative (right) anterior curvature Orbscan maps of the left eye before and 4 years after implantation of two intracorneal ring segments. The maximal keratometry and corneal cylinder decreased by $7.1 \mathrm{D}$ and $2 \mathrm{D}$ respectively

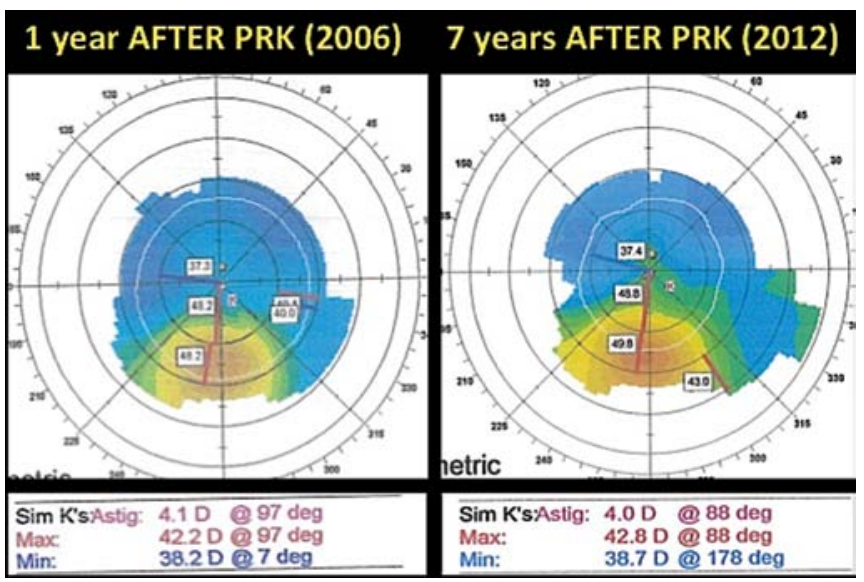

Fig. 2: One year (left) and 7 years (right) postoperative anterior curvature Orbscan maps of the left eye after the photorefractive keratectomy procedure. We note the corneal topographic stability with an increase of only $0.6 \mathrm{D}$ in maximal keratometry and no progression of corneal cylinder

(KC) ${ }^{17}$ forms fruste $\mathrm{KC}^{12}$ and $\mathrm{KC}$ suspect eyes ${ }^{15}$ have been successfully performed, with good intermediate and longterm refractive outcomes reported, and more importantly, topographic stability. Forms fruste $\mathrm{KC}$ and $\mathrm{KC}$ have been clearly identified as major risk factors of keratectasia. ${ }^{18}$ However, interestingly, several reports have suggested the potential interaction of surface ablation on keratoconus progression, following reports where eyes treated with PRK remained stable over years whereas their fellow eyes treated with LASIK developed ectasia. ${ }^{14,15-20}$ Experimental studies on rabbit corneas have suggested that keratoconus stabilization after excimer laser treatment might occur due to deposition of newly synthesized collagen in the extracellular matrix of the anterior corneal stroma and that the removal of central corneal lamellae would induce relaxation of the peripheral collagen fibrils toward their limbal base, improving the anterior protrusion..$^{21,22}$ Other hypothesis have also been proposed for explaining the potential halting effect of PRK on KC progression, such as the removal of the central anterior stroma and Bowman lamina where histopathologic alterations are prevalently seen in $\mathrm{KC}$ eyes ${ }^{14}$ or rather, a focal corneal cross-linking induced by postoperative inflammation and corneal healing, which might strengthen the corneal collagen fibers by linking one polymer chain to another. ${ }^{15}$ Intraoperative excimer laser ultraviolet- $\mathrm{C}$ radiation associated to environmental ultraviolet exposure on a cornea with no Bowman layer has also been evoked regarding its possible similar stiffening effect as corneal collagen cross-linking with riboflavin and ultraviolet A light. ${ }^{14}$

In our case, we also report a long-term refractive and topographic stability after PRK ablation in a severe $\mathrm{KC}$ cornea. However, it has to be mentioned that the first case of ectasia after PRK has been reported in $2006,{ }^{13}$ a year after our patient had undergone a PRK procedure, and although the situation significantly improved, we do not recommend in a daily practice, to perform a high PRK ablation in KC corneas.

The particularity of the case being reported is that the cornea remained stable despite a high PRK ablation of about $43 \%$ of the total preoperative corneal thickness. One might hypothesize that it might have some synergistic or additive effect for halting the $\mathrm{KC}$ progression with the intracorneal rings implanted 4 years before. Long-term stability after ICRS implantation has already been reported in 2007 by Kymionis et $\mathrm{al}^{5}$ over a period of 5 years, and later by Bedi and $\operatorname{Colin}^{6}$ who evaluated the long-term rate of ectasia progression in eyes that were implanted with INTACS rings. The authors reported more than $92 \%$ of progressive $\mathrm{KC}$ stabilized with the procedure, suggesting a potential halting effect of ICRS on the KC progression. However, its mechanism remains unclear, as Intacs have been shown not to affect corneal strength ${ }^{23,24}$ but rather a reshaping of the cornea with a central flattening.

Does the INTACS rings have helped maintaining the corneal shape marked by the laser ablation or played a significant role in the prevention of corneal protrusion remain unaddressed. Nevertheless, the combination of fibrosis induced after PRK in a relatively older keratoconic patient (with regards to the natural kinetic of the disease progression) as well as the non-documented progression of the KC preoperatively, might have certainly contributed to corneal stability overtime. Further comparative and randomized studies are necessary to better understand the response of keratoconic corneas to combined treatments. Meanwhile, we do not recommend to perform high PRK ablation in keratoconus. 


\section{REFERENCES}

1. Fleming JF, Wan WL, Schanzlin DJ. The theory of corneal curvature change with the intrastromal corneal ring. The CLAO Journal 1989;15(2):146-150.

2. Colin J, Cochener B, Savary G, Malet F. Correcting keratoconus with intracorneal rings. J Cataract Refract Surg 2000;26(8):11171122.

3. Piñero DP, Alio JL. Intracorneal ring segments in ectatic corneal disease-a review. Clinical and experimental ophthalmol. 2010;38(2):154-167.

4. Health Quality Ontario. Intrastromal corneal ring implants for corneal thinning disorders: an evidence-based analysis. Ontario Health Technology Assessment Series 2009;9(1):1-90.

5. Kymionis GD, Siganos CS, Tsiklis NS, et al. Long-term followup of Intacs in keratoconus. Am J Ophthalmol 2007;143(2):236244.

6. Bedi R, Touboul D, Pinsard L, Colin J. Refractive and topographic stability of Intacs in eyes with progressive keratoconus: five-year follow-up. J Refract Surg 2012;28(6):392-396.

7. Alió JL, Artola A, Claramonte PJ, Ayala MJ, Sánchez SP. Complications of photorefractive keratectomy for myopia: two-year follow-up of 3000 cases. J Cataract Refract Surg 1998;24(5):619-626.

8. Vestergaard AH, Hjortdal J, Ivarsen A, et al. Long-term outcomes of photorefractive keratectomy for low to high myopia: 13 to 19 years of follow-up. J Refract Surg 2013;29(5):312-319.

9. Reznik J, Salz JJ, Klimava A. Development of unilateral corneal ectasia after PRK with ipsilateral preoperative forme fruste keratoconus. J Refract Surg 2008;24(8):843-847.

10. Bardocci A, Abad JC, Tamburrelli C, et al. Early onset keratectasia after photorefractive keratectomy in a case showing Vertical D topographic pattern. Seminars in Ophthalmology. 2012;27(3-4):52-55.

11. Mortensen J, Ohrström A. Excimer laser photorefractive keratectomy for treatment of keratoconus. J Refract Corn Surg 1994;10(3):368-372.

12. Koller T, Iseli HP, Donitzky C, et al. Topography-guided surface ablation for forme fruste keratoconus. Ophthalmology 2006;113(12):2198-2202.

13. Malecaze F, Coullet J, Calvas P, et al. Corneal ectasia after photorefractive keratectomy for low myopia. Ophthalmology. 2006;113(5):742-746.

14. Khochtali S, Colin J, Touboul D, Binder PS. Does photorefractive keratectomy affect keratoconus progression? J Refract Surg 2010;26(12):925-926.

15. Guedj M, Saad A, Audureau E, Gatinel D. Photorefractive keratectomy in patients with suspected keratoconus: five-year follow-up. J Cataract Refract Surg 2013;39(1):66-73.

16. Kamiya K, Shimizu K, Ohmoto F. Comparison of the changes in corneal biomechanical properties after photorefractive keratectomy and laser in situ keratomileusis. Cornea. 2009;28(7):765-769.

17. Cennamo G, Intravaja A, Boccuzzi D, Marotta G, Cennamo G. Treatment of keratoconus by topography-guided customized photorefractive keratectomy: two-year follow-up study. J Refract Surg 2008;24(2):145-149.

18. Randleman JB, Woodward M, Lynn MJ, Stulting RD. Risk assessment for ectasia after corneal refractive surgery. Ophthalmology 2008;115:37-50.

19. Kymionis GD, Tsiklis N, Karp CL, Kalyvianaki M, Pallikaris AI. Unilateral corneal ectasia after laser in situ keratomileusis in a patient with uncomplicated photorefractive keratectomy in the fellow eye. J Cartaract Refract Surg 2007;33(5):859-861.

20. Hodge C, Lawless M, Sutton G. Keratectasia following LASIK in a patient with uncomplicated PRK in the fellow eye. J Cartaract Refract Surg 2011;37(3):603-607.

21. Wollensak G, Spoerl E, Seiler T. Riboflavin/ultraviolet-a induced collagen crosslinking for the treatment of keratoconus. Am J Ophthalmol 2003;135:620-627.

22. Wollensak G, Wilsch M, Spoerl E, Seiler T. Collagen fiber diameter in the rabbit cornea after collagen crosslinking by riboflavin/UVA. Cornea 2004;23:503-507.

23. Dauwe C, Touboul D, Roberts CJ, et al. Biomechanical and morphological corneal response to placement of intrastromal corneal ring segments for keratoconus. J Cataract Refract Surg 2009;35(10):1761-1767.

24. Piñero DP, Alio JL, Barraquer RI, Michael R. Corneal biomechanical changes after intracorneal ring segment implantation in keratoconus. Cornea 2012 May;31(5):491-499.

\section{ABOUT THE AUTHORS}

\section{Sina Elahi}

Intern, Department of Ophthalmology, Anterior Segment and Refractive Surgery Unit, University Hospital of Bordeaux, France

\section{Olivier Rahimian}

Resident, Department of Ophthalmology, Anterior Segment and Refractive Surgery Unit, University Hospital of Bordeaux, France

\section{David Touboul}

Refractive Surgeon, Department of Ophthalmology, Anterior Segment and Refractive Surgery Unit, University Hospital of Bordeaux, France

\section{David Smadja (Corresponding Author)}

Refractive Surgeon, Department of Ophthalmology, Anterior Segment and Refractive Surgery Unit, University Hospital of Bordeaux, France Phone: 0033556795679, e-mail: davidsmadj@hotmail.fr 